\title{
La política petrolera en el Gobierno de la Revolución Ciudadana
}

\section{Oil policy in the "Revolución Ciudadana" Government}

\author{
NELSON GARCÍA OSORIO \\ Universidad Tecnológica Equinoccial. Quito \\ Correo electrónico: nelgarciaosorio@hotmail.com
}

RECIBIDO: 01 septiembre 2014 / APROBADO: 07 noviembre 2014

\section{Resumen}

La presente investigación tiene como objetivo analizar la ventaja de la política petrolera en el actual régimen, para lo cual se realiza un resumen del manejo del petróleo a partir de 1972, se describe la política petrolera aplicada por los gobiernos, desde la administración del doctor Oswaldo Hurtado hasta la administración del economista Rafael Correa, se analiza el entorno jurídico en el marco de la Ley de Hidrocarburos y de la Constitución de la República del Ecuador. Se concluye con algunas consideraciones que llaman a la reflexión cuando se ejecuta un contrato cuyo beneficio no es el mejor para el país como es en el caso del campo Sacha.

PALABRAS CLAVE: Política petrolera, contratos, Sacha

\begin{abstract}
:
This research aims to analyze the advantage of the Petroleum Policy under the current regime, for which a summary of the management of oil is from 1972, applied for government oil policy is described, from the administration of Dr. Oswaldo Hurtado to the administration of Rafael Correa, the legal environment is analyzed in the framework of the Hydrocarbons Law and the Constitution of the Republic of Ecuador. It concludes with some considerations that call for reflection when a contract whose benefit is not the best for the country as is the case of Campo Sacha runs.
\end{abstract}


KEYWORDS: Oil policy, contracts, Sacha

CLASIFICACIÓN JEL: F40, F49.

\section{Introducción}

El petróleo es uno de los negocios más rentables del mundo, razón por la cual, para lograr el control de las reservas petroleras algunos países han sido invadidos.

Al mismo tiempo, el petróleo es cada vez es más escaso y, su extracción y procesamiento son cada vez más caros.

La expansión global del modelo de desarrollo "extractivista", provocaquecadadía másconsumidores pugnen por reservas de recursos naturales, las cuales que se vuelven paulatina e inexorablemente escasas. Esta disyuntiva ha activado una tensa competencia entre estados y agentes diversos por el acceso a las materias primas.

En Ecuador, la mayor parte de energía utilizada proviene del petróleo y del gas natural, de igual manera, el petróleo es uno de los principales rubros de ingreso para el Estado.

La política energética del actual Gobierno impulsó una reforma parcial a la Ley de Hidrocarburos, en cuanto a la explotación petrolera, permitió que de "contratos de participación" se cambie a la de "prestación de servicios" y "servicios específicos"; este último, con empresas estatales para que manejen campos petroleros en producción, sin ningún riesgo exploratorio.

\section{Antecedentes}

Durante los últimos 35 años de régimen democrático ${ }^{1}$, varios gobiernos han aceptado las condiciones del Fondo Monetario Internacional a través de la suscripción de las cartas de intención.

En 1972 se inició la explotación del petróleo en la región amazónica, siendo también el inicio de un exagerado endeudamiento externo. En el mencionado año el saldo de la deuda era de 241.5, para 1990 paso a 11.855.6 millones de dólares (Llanes, 2008), en este periodo la deuda creció a una tasa promedio del 24 por ciento, para cumplir con las obligaciones de pago a los organismos acreedores, estos obligaron a los

\footnotetext{
1 Tras nueve años de dictadura, la democracia en el Ecuador empezó en el año de 1979 con el presidente Jaime Roldós, después de su muerte vendría el segundo presidente Oswaldo Hurtado quien fue vicepresidente de Roldós, luego León Febres Cordero, Rodrigo Borja y Sixto Duran Ballén quienes a pesar de gobernar con dificultades lograron terminar sus períodos. Más tarde vendría el sexto presidente Abdalá Bucaram cuyo gobierno tuvo mucha corrupción, principalmente por esta razón terminó huyendo a Panamá como exiliado. Después de que el país estuvo en un caos tras la salida de Bucaram, Rosalía Arteaga fue presidenta por un día siendo sustituida por Fabián Alarcón quien sería el séptimo presidente.

Elegido por votación del pueblo en 1998 el octavo presidente fue Jamil Mahuad, luego del derrocamiento de este subió al poder el vicepresidente Gustavo Noboa. El siguiente mandatario elegido por el pueblo fue el décimo presidente Lucio Gutiérrez, quien por una rebelión de forajidos salió del poder siguiéndole Alfredo Palacio, el décimo primer presidente, quien fue vicepresidente de Gutiérrez. Rafael Correa es presidente número doce que actualmente tenemos.
} 
gobiernos de turno a poner en vigencia políticas de ajuste para estabilizar la economía.

El Estado no disponía de recursos para realizar inversiones en el área petrolera, de tal manera que el gobierno de Oswaldo Hurtado creó el "contrato de prestación de servicio". Posteriormente, el gobierno de Sixto Durán Ballén, a inicios de los años noventa creó la "Ley de Modernización del Estado, privatizaciones, y prestación de los servicios por parte de la iniciativa privada" y nuevos contratos petroleros de "participación y de campos marginales" con incentivos tributarios.

Cabe señalar que el cambio de los contratos petroleros no faculta la Ley de Hidrocarburos, sino solamente permite su modificación en el caso, si conviniere a los intereses del Estado (Ley de Hidrocarburos, 2010)².

El gobierno de Gustavo Noboa Bejarano, prefirió crear un "convenio de alianza estratégica" que le permitió suscribir en forma directa contratos de "servicios específicos" con empresas petroleras estatales, obviando el proceso licitatorio.

La actual Constitución Política del Estado señala que los recursos naturales no renovables, considerados como un sector estratégico, son de propiedad del Estado.

El gobierno del presidente Rafael Correa, mantiene políticas inspiradas en el manejo neoliberal del sector hidrocarburos, reflejadas en la extracción de los recursos naturales, en gran parte por empresas internacionales. Esta manera de manejar el petróleo se considera como una fuente de desarrollo, situación cuestionable por el decrecimiento natural de las reservas del petróleo. Además, no sólo se trata de administrar y usar correctamente los recursos naturales, sino de cambiar la modalidad de exportación primaria, que nos ha llevado a un alto grado de dependencia con los países desarrollados que disponen de tecnología de punta.

\footnotetext{
2 Art.31-A, p. 17
}

La política petrolera del presidente Correa ha impulsado una reforma parcial a la Ley de Hidrocarburos, cambiando los "contratos de participación" por los de "prestación de servicios". Así como también promovió los contratos de "servicios específicos" con empresas estatales para que manejen campos petroleros en producción, sin ningún riesgo exploratorio. En ese marco se creó la empresa de economía mixta Río Napo ${ }^{3}$.

El contrato de "servicios especificos" manifiesta la transferencia de tecnología y la inyección de capital extranjero para incrementar la producción de manera gradual, partiendo de una curva base, explicada técnicamente de acuerdo a la producción histórica.

Ante la necesidad del Gobierno de disponer de más recursos económicos para solucionar ciertos problemas, en el caso de Ecuador, se sigue con un modelo extractivista, planteado como la "extracción responsable" de los recursos, mientras que otros actores políticos proponen no incrementar la extracción de los recursos naturales.

Según los expertos en energía, la producción mundial de petróleo llegará algún día, a un momento máximo o "pico" de producción diaria, seguido de una caída cada vez más brusca del suministro.

El mayor productor de petróleo es Medio Oriente, su participación es cerca de la tercera parte. Europa Oriental y América Latina son también grandes productores (Figura No.1), la mayor parte de la producción de estas regiones es para exportación, mientras que para los Estados Unidos su producción no alcanza a cubrir su consumo doméstico.

\footnotetext{
${ }^{3}$ Los términos de referencia del Contrato de Servicios específicos para la explotación y administración petrolera en el campo Sacha, contempla la participación del Gobierno ecuatoriano, a través de Petroecuador, en un $70 \%$, mientras que el Gobierno venezolano a través de PDVESA participa con un 30\%, comprometiéndose a incrementar el volumen de producción, a partir de la firma del contrato, en noviembre del 2009.
} 
Figura 1.

Producción mundial de petróleo por región 2010

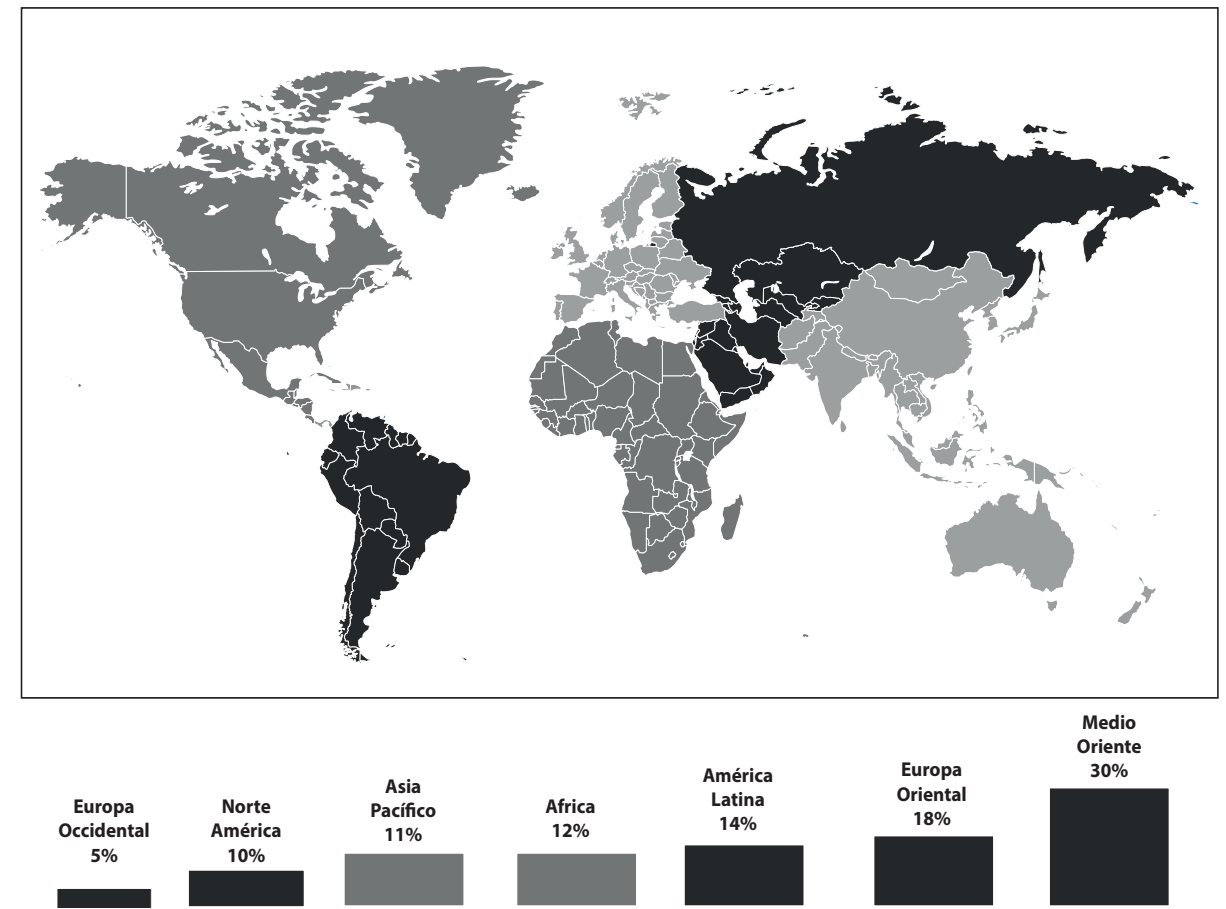

Fuente: EP Petroecuador, Informe Estadístico (2010) y, Global Energy Statistical Yearbook (2011), en http://yearbook.enerdata.net

La expansión global del modelo "extractivista de desarrollo" provoca que cada día más consumidores pugnen por reservas de recursos naturales que se vuelven paulatina e inexorablemente escasas. En la actualidad los gobiernos tienden a un nacionalismo de los recursos porque estos son considerados estratégicos. Hoy la mayoría de las principales compañías petroleras en el mundo son empresas estatales.

Klare (2010) citado por Microdinero (2010), experto mundial en políticas de energía y recursos, advierte que el mundo se encuentra a las puertas de una nueva guerra fría: el control del petróleo va a definir, en pocos años, el mapa geopolítico de la Tierra. Este autor desmenuza la emergencia de un orden mundial signado por la variable energética debido de que las materias primas, y del petróleo en concreto están disminuyendo.
De tal manera que la producción de petróleo no se logrará incrementar en el volumen deseado para satisfacer las futuras demandas mundiales. Los resultados serán: permanentes altos precios; fuerte competencia internacional por los suministros disponibles; y, escasez periódica causada por tensiones políticas y sociales en los países productores de petróleo (Klare, 2005) citado por (Rebelión, 2005).

La actual política petrolera del Ecuador está impulsando el manejo del petróleo a través de la modalidad de contratos de obras o servicio específicos, detallada en las páginas posteriores; $y$, por prestación de servicios. Esta modalidad de prestación de servicios contempla que el Estado reembolsa todos los gastos operacionales en la exploración y explotación del petróleo a la empresa contratista, solo si hubiere encontrado hidrocarburos comercialmente explotables, la diferencia se reparten entre el Estado 
y la empresa, de acuerdo con lo establecido en el contrato. Mientras que los contratos de participación ya no se ejecutan en el país, porque el Estado perdía de manera permanente en la participación de la producción.

\section{Sistema de explotación de los recursos naturales, especialmente del petróleo}

Los países ricos en recursos naturales, cuya economía se sustenta prioritariamente en una economía primarioexportadora de recursos petroleros y/o minerales, característica de muchos países subdesarrollados llevaría a afirmar que, los países que dependen de la extracción y exportación de los recursos naturales encuentran mayores dificultades para desarrollarse (Acosta, 2009).

La gran disponibilidad de recursos naturales que caracteriza a los países subdesarrollados, particularmente si se trata de minerales o petróleo, tienden a distorsionar la estructura económica y la asignación de los factores productivos del país; [...] (Acosta, 2009).

Este tipo de economías primario-exportadoras tienen orígenes coloniales. Desde 1492 se inicia las primeras identidades históricas cuyo proceso se denomina hoy, globalización. Funciona con una elevada demanda de capital y tecnología, sin una planificación integradora de esas actividades primario-exportadoras al resto de la economía y de la sociedad, el aparato productivo no es competitivo con otros países de similares condiciones, creando una dependencia de los mercados foráneos.

Todos o casi todos los países cuya economía está ligada la exportación de recursos primarios, tienen la necesidad de aumentar el volumen de extracción de dichos recursos lo que beneficia a los países que tienen capital y tecnología.

Los países beneficiados y el subdesarrollo de la periferia no son situaciones independientes, sino todo lo contrario, las dos situaciones son inseparables.

\section{Entorno jurídico en el contexto de los recursos naturales}

El petróleo en décadas anteriores se constituyó en la principal fuente de ingresos estatales, sin embargo, su manejo requiere de un marco jurídico e institucional que facilite un mayor control y participación del Estado.

\section{Constitución de la República del Ecuador}

La Constitución de la República $(2008)^{4}$ señala que se consideran sectores estratégicos: la energía en todas sus formas; las telecomunicaciones; los recursos naturales no renovables; el transporte y la refinación de hidrocarburos; la biodiversidad y el patrimonio genético; el espectro radio eléctrico; el agua y los demás que determine la ley.

El Estado podrá delegar la participación en los sectores estratégicos y servicios públicos a empresas mixtas [...]. Los recursos naturales no renovables pertenecen al patrimonio inalienable e imprescriptible del Estado. En su gestión, el Estado priorizará la responsabilidad intergeneracional, la conservación de la naturaleza, [...].

La propiedad de los recursos naturales son de propiedad inalienable, imprescriptible e inembargable del estado los recursos naturales no renovables y, en general, $[\ldots]$.

La modificación del contrato de prestación de servicios para la exploración y explotación de hidrocarburos, modificó el pago de la tarifa por cada barril producido, como manifiesta Llanes (2011) en redciecuador (2011) a los cuatro años del gobierno de Correa, se impulsó una reforma parcial a la Ley de Hidrocarburos, se realizó sobre la base del contrato de prestación de servicios creada en 1982 por iniciativa del gobierno de Oswaldo Hurtado.

\footnotetext{
4 Capítulo quinto, sectores estratégicos, servicios y empresas públicas Art. 313, inciso tercero. Arts. 316, 317 y sección $4^{\mathrm{a}}$ Recursos naturales Art. 408.
} 
Así como también se aplican los contratos de obras o servicios específicos, que consiste en entregar sin licitación los principales campos petroleros en los cuales ya no existe riesgo exploratorio, como son: Sacha, Shushufindi, Cononaco, entre otros, a empresas estatales o subsidiarias de estas. En estos campos petroleros se han invertido miles de millones de dólares del pueblo ecuatoriano para descubrir reservas comercialmente explotables.

\section{Ley de Hidrocarburos}

Los yacimientos de hidrocarburos son patrimonio del Estado, de tal forma que en todas las actividades de hidrocarburos se prohíben prácticas o regulaciones que impidan o distorsionen la libre competencia por parte del sector privado o público. Así como también prácticas o acciones que pretendan el desabastecimiento deliberado del mercado interno de hidrocarburos (RO-S, 2000).

El Estado explorará y explotará en todas las actividades de hidrocarburos en forma directa a través de las empresas públicas de hidrocarburos. De manera excepcional podrá delegar el ejercicio de estas actividades a empresas nacionales o extranjeras, [...]. (RO-S 244, 2010). Cabe señalar que la Secretaria de Hidrocarburos es el administrador de los contratos antes mencionados, salvo en el caso de contratos de obras y servicios específicos ${ }^{5}$.

Ley de Hidrocarburos $(2010)^{6}$ los contratos de obras o servicios específicos a que se refiere el inciso segundo

\footnotetext{
5 La Ley reformatoria a la Ley de Hidrocarburos y a la Ley de Régimen Tributario Interno, sin numeración, (L. s/n. RO-S 244: 27 de julio 2010), reformó a la Ley de Hidrocarburos (DS-2967. RO 711: 15 de noviembre de 1978), y en su artículo 18 dispone: “...sustitúyase la palabra PETROECUADOR por la frase $\mathrm{La}$ Secretaría de Hidrocarburos; y en general, toda referencia a PETROECUADOR como signatario o administrador de contratos y/o áreas se entenderá que se trata de la Secretaría de Hidrocarburos, salvo en el caso de contratos de obras y servicios específicos;....".
}

6 Art.17 del artículo dos ${ }^{7}$ son aquellos en que personas jurídicas se comprometen a ejecutar para PETROECUADOR, obras, trabajos o servicios específicos, aportando la tecnología, [...].

\section{Sistema especial de licitaciones y reglamentos}

El interés de las contratistas es obtener una mayor renta petrolera, obviando el proceso licitatorio, como sucede con los contratos de servicios específicos. Situación que se dio también con el negocio de la telefonía celular renovado por el gobierno del Econ. Correa en el 2008 por 15 años más.

Los contratos de servicios específicos deberían ser solamente para los contratos de campos marginales, yacimientos cuya producción en el momento de la licitación es inferior o igual al 1\% de la producción nacional, como lo señala la Ley de Hidrocarburos. Sin embargo, en este tipo de contrato se aplica lo siguiente: la adjudicación de los contratos a los que se refieren los Artículos 1, 2, y 3 de esta Ley la efectuará el Ministerio Sectorial mediante licitación, con excepción de los que se realicen con empresas estatales (Ley de Hidrocarburos, 2010).

\footnotetext{
${ }^{7}$ Son contratos de exploración y explotación de campos marginales aquellos celebrados por el Estado por intermedio de la Secretaría de Hidrocarburos, mediante los cuales se delega a la contratista con sujeción al numeral primero del artículo 46 de la Constitución Política de la República (RO 449: 20-oct-2008), la facultad de exploración y explotación adicional en los campos de producción marginal actualmente explotados por PETROPRODUCCIÓN, realizando todas las inversiones requeridas para la exploración y explotación adicional.

${ }^{8}$ Ley de Hidrocarburos, actualizada a julio 2011, Art. 19 incisos primero, p. 11
} 


\section{Conclusiones}

El Ecuador mantiene una política extractivista y una economía dependiente del petróleo, razón por la cual los gobiernos siempre quieren incrementar el volumen de extracción de crudo, inclusive el considerado como pesado (menos de 10 grados API).

El presidente Rafael Correa, ha promovido contratos petroleros de "prestación de servicios" y de "servicios específicos", como es el caso con la Operadora Río
Napo Compañía de Economía Mixta, ORNCEM, para que maneje el campo Sacha, desde noviembre del 2009, sin ningún riesgo exploratorio y con reservas probadas $^{9}$. El campo Sacha es el de mayor producción de crudo liviano, considerado como "la joya de la corona", históricamente administrado por el Estado.

\footnotetext{
9 Reservas probadas son aquellas que la industria considera
} que pueden ser recuperadas en las condiciones económicas y operativas existentes.

\section{Referencias bibliográficas}

- Acosta, A. (2009) La maldición de la abundancia, Ediciones Abya-Yala. Quito, p.22

- Enerdata (2011) Energy Statistical Yearbook. Recuperado en diciembre 2012 de http://yearbook.enerdata.net

- Klare, M. (2010), Reseña la nueva geopolítica de la energía. Recuperado en enero 2013 de http://www. microdinero.com/nota.php?subseccion $=$ F1\&notId $=2228$

- Klare, M. (2005), El ocaso de la era del petróleo. Recuperado en enero 2013 de http://www.rebelion.org/ noticia.php?id=20053

- Legislación Codificada (2011), Constitución de la República del Ecuador, Corporación de Estudios y Publicaciones. Quito, p. 211 y 262

- Legislación Codificada (2011), Ley de Hidrocarburos, Corporación de Estudios y Publicaciones, Versión Básica. Quito, Art.17 y 18 p. 9; Art. 18.1 inciso segundo y cuarto p. 10; Art. 19 incisos primero y segundo, p. 11

- Legislación Codificada (2011), Ley de Hidrocarburos, Corporación de Estudios y Publicaciones, Versión Básica. Quito, Art.31-A, p. 17

- Legislación Codificada (2011) Registro Oficial-Suplemento No. 144, 18 de Agosto del 2000. Art. 1.A

- Ley s/n (2010) Registro Oficial-Suplemento No. 244, 27 de Julio del 2010. Art.1, p.3

- Llanes,H. (2011) Ecuador: Reforma petrolera y la desnacionalización de los hidrocarburos. Recuperado en enero 2013 de http://redciecuador.wordpress.com/

- Llanes,H. (2008) Contratos petroleros, inequidad en el reparto de la producción, Quito, Artes Gráficas SILVA, pág. 44

- Yergin, D. (1992) citado por Llanes, H. (2011) Ecuador: Reforma petrolera y la desnacionalización de los hidrocarburos. Recuperado en enero 2013 de http://redciecuador.wordpress.com/ 